\title{
Strategies for the Successful Implementation of Viral Laboratory Automation
}

\author{
Cristóbal Avivar*
}

Integrated Areas of the Biotechnology Laboratory, Hospital de Poniente, Ctra de Almerimar S/N, Spain

\begin{abstract}
It has been estimated that more than $70 \%$ of all medical activity is directly related to information providing analytical data. Substantial technological advances have taken place recently, which have allowed a previously unimagined number of analytical samples to be processed while offering high quality results. Concurrently, yet more new diagnostic determinations have been introduced - all of which has led to a significant increase in the prescription of analytical parameters. This increased workload has placed great pressure on the laboratory with respect to health costs. The present manager of the Clinical Laboratory (CL) has had to examine cost control as well as rationing - meaning that the CL's focus has not been strictly metrological, as if it were purely a system producing results, but instead has had to concentrate on its efficiency and efficacy. By applying re-engineering criteria, an emphasis has had to be placed on improved organisation and operating practice within the CL, focussing on the current criteria of the Integrated Management Areas where the technical and human resources are brought together. This re-engineering has been based on the concepts of consolidating and integrating the analytical platforms, while differentiating the production areas (CORE Laboratory) from the information areas. With these present concepts in mind, automation and virological treatment, along with serology in general, follow the same criteria as the rest of the operating methodology in the Clinical Laboratory.
\end{abstract}

Keywords: Laboratory management, re-engineering, integration, consolidation, core-lab, virological automation.

\section{INTRODUCTION}

In order to fully grasp the viral automation strategies taking place in the Clinical Laboratory, and the resulting improvements and impact that automation provides, it is important to look at the new criteria and ideas for the organization of modern biotechnology labs and areas.

The global automation processes developed over the last few years in microbiology can only be considered partially successful given that microbiology is currently sandwiched between conventional culture automation on analytical platforms, on the one hand, and mass spectrometry for identification and sensitivity assays on the other. Studies reporting potential for improvement have already been published [1], but the same does not hold true for serology and, consequently, nor does it for virology. Over the last decade, the detection of both antigens and antibodies has been carried out on conventional immunochemistry platforms. This chapter will highlight how the automation of viral detection tests, and the improvements that result, are on a par with biochemical and immunochemical profitability parameters.

The role played by labs in clinical decision-making processes is such that, according to the literature, it is estimated that over $70 \%$ of medical interventions are directly related to the information provided by analytical data $[2,3]$. For this reason, labs are a valuable source of information for

*Address correspondence to this author at the Integrated Areas of the Biotechnology Laboratory, Hospital de Poniente, Ctra de Almerimar S/N, El Ejido 04700, Almería, Spain; Tel: 0034950022 746; Fax: 950022601;

E-mail: cristobal.avivar@ephpo.es public health care systems regarding diagnosis, prognosis and patient care, amongst other health-related issues.

Furthermore, the last few years have witnessed significant breakthroughs in Clinical Laboratories (CL) with improved precision and accuracy. New biochemistry, immunochemistry and hematology auto-analyzers have provided high sample processing speeds, making it now possible to process an unprecedented number of patient tests and ensure high-quality results.

Both aspects have greatly contributed to a significant increase in analytical parameter prescriptions as a critical information source for clinical diagnosis.

\section{OVER-PRESCRIPTION AND COST}

The simplification of the whole process has led to substantial over-prescription - with higher test frequency, further new tests being introduced along with rapid diagnostic tests. This has gone hand in hand with a decrease in value perception and a cost rise generated by increasing lab tests [4].

Unequivocal data on the financial impact of these developments are not currently available, for reasons such as the differences between particular labs and between regional diagnostic criteria, as well as the lack of cost allocation criteria and non-participation in benchmarking programs $[5,6]$. For these and other reasons, we need to keep in mind several factors while estimating lab costs - what percentage they account for in the hospital budget, in the health care area and in the health care system as a whole. Clinical Leadership \& Management reports a planning methodology implemented in the US for laboratory integration, estimating 
labs costs ranging from 4.5 to $10 \%$ of total health care expenditure [7]. A recent SEQC (Spanish Society of Clinical Chemistry) report by Dr. Álvarez and Dr. Caballé estimated global lab costs at $5 \%$ of total health care expenditure, and found a 40\% increase in analytical testing between 1999 and 2008. This, according to the authors, means that, based on Spain's population, an average of 21.55 lab tests are currently performed per inhabitant [8].

Such an increase signifies that laboratory costs are putting a great burden on health care budgets and, indeed, some well-regarded calculations consider that laboratory costs in Europe have increased by $130 \%$ in recent decades. This situation has led lab managers to search for innovative ways to control costs without cutting efficiency or quality.

In our Laboratory Area, costs related to Relative Value Units (RVU) or Relative Cost Unit (RCU) [9] increased by 134\% between 2004 and 2011; whereas the parameter production cost increased by $142 \%$ over the same period. The only exception in our case has been the cost per unit, which not only stopped increasing, but even went down slightly thanks to our reorganizing and reengineering process, after the implementation of all the management criteria (discussed later in this article) throughout the lab area $[10,11]$.

\section{COST CONTROL MEASURES FOR CLINICAL LABORATORIES}

There are two types of lab managers to be found in staterun and private healthcare organizations. As a general rule, those belonging to the first group do not belong to the organization proper and are located outside the laboratory structure, focusing solely on economically-driven models that have an immediate but short-lived financial impact. The other group are clinical laboratory heads or managers, who combine a purely financial approach with cost-effectiveness criteria [3].

Currently, we can find a whole army of new directeconomy managers - they apply exclusively financial criteria in order to lower the costs of laboratory testing instantly via direct economy-based systems, paying no attention to clear rationalization criteria. They propose quite dramatic ideas such as the linear reduction of direct costs, yet they fail to assess indirect costs. They ask for the implementation of novel ideas such as per capita payment (unit cost per patient) [12], as well as a whole plethora of new, initially efficient ideas (from a financial point of view) but which, in the midterm, destabilize the lab's financial health and long-term viability.

Conversely, we can find knowledge-based managers who are experts in laboratory-applied economics able to reconcile financial criteria with the global health-related criteria relevant to laboratories, understanding the impact of indirect costs on profits. Experts such as these are totally convinced that, using clear criteria for the reorganization of work areas and laboratories as a whole, along with the implementation of new technologies provided by the industry, excellent results can be achieved in the mid to long term.

\section{LAB MANAGERS, A NEW PROFESSIONAL PROFILE}

In line with Good Laboratory Practices (GLP), lab managers must be closely involved with controlling laboratory performance and rationalizing costs. In the present climate, it is simply not acceptable to approach clinical laboratory management from a strictly metrological point of view, to consider them only as result-driven systems, without involving their staff in efficiency and efficacy issues. Present-day lab managers need to use a more holistic approach, managing technical and human resources globally in order to achieve real financial profitability that includes both maximum efficiency and quality for the patients' benefit.

These new professionals are deeply knowledgeable of the latest technological developments for clinical laboratories. They are also able to combine economic reality with professional know-how, applying innovative yet realistic ideas to lab management and to invest in future projection and efficiency strategies looking not only at the short-term but also the long-term impact. For this reason, lab managers design "organizational improvement strategies" focused on overall performance and on improvements in work and knowledge areas.

\section{NEW ORGANIZATION FOR CLINICAL LABORA- TORIES -INTEGRATED AREAS}

In order to achieve the goals previously described, it is critical to start with a complete laboratory reengineering process based primarily on organizational criteria, which will in turn lead directly and painlessly to improved financial performance $[1,13-15]$.

Reorganization processes have had a great impact in Spain. In the past, Spanish laboratories used to be designed as small islands both from an architectural and a functional point of view; each island hosted its own sub-specialty areas and each minor area functioned in isolation from the others, responsible for its own management, production and information base.

In contrast, new laboratories, conceived as Integrated Management Areas, combine and share resources. There are several different models in place. By way of an example, I will briefly discuss our own hospital lab, in which the diagnostic department encompasses all human and technical activities, as well as the infrastructural resources needed for patient care in the clinical testing specialty areas of clinical biochemistry, molecular biology, hematology, hemotherapy, microbiology, serology, clinical parasitology and anatomical pathology.

The integration of laboratories as global management blocks ensures a more rational use of resources, avoiding technical, instrumentational and staff overlaps, as well as improving workflows and applying efficiency criteria better.

This global management system allows for greater device capabilities and a higher automation level, which in turn leads to higher staff efficiency since it reduces the need for additional support and unproductive tasks. Furthermore, it 
does not only have financial advantages, but also a positive impact on the quality of lab results and diagnostic efficiency.

Integration includes adapting work areas, sharing rooms and technology, as well as combining support tasks (administration, maintenance, logistics, information technology (IT), quality assurance systems, training, research and so on).

\section{PRODUCTION AND THE CORE LAB}

Regardless of a lab's complexity and equipment, current criteria for cost-effectiveness improvements are based on the establishment and differentiation of production areas (CORE Lab). These bring together the technological capabilities of all diagnostic areas for the "consolidation and integration" of testing platforms $[13,16]$. The area encompasses the different specific knowledge areas, in which each professional is responsible for developing their clinical expertise, based on their training, professional development and involvement in the lab - while always responsive to the notion of process reengineering.

In order to achieve this goal without losing sight of the highest possible profitability, it is critical to apply these allimportant reengineering criteria sensibly. Thanks to the substantial technological breakthroughs achieved in the last few decades, it is not only possible to apply them, but also to keep improving them. For this reason, it is essential to understand how to conceptually and formally implement consolidation criteria for testing platforms and how to integrate them.

These ideas have given rise to the CORE lab. Broadly speaking, its main goal is to improve and bring together the greatest possible amount of automated lab procedures with the lowest possible number of testing platforms (consolidation). Ideally, an analytical platform includes the greatest possible number of tests, obviously without forsaking certain quality standards, speed and processing capabilities that meet the lab's needs. Biochemistry and immunochemistry platforms currently offered on the market by diagnostics companies are very much in line with these requirements. Furthermore, these companies are increasingly working on creating new testing platforms that will be able to carry out numerous tests at high speed. Thanks to the efforts from the diagnostics industry, we are seeing more and more products that meet the necessary criteria.

In order to make this consolidation process effective, platforms have to include the greatest possible number of parameters. However, this requirement is often compromised by commercial criteria set by suppliers [1] or else by their lack of knowledge. For this reason, it is critical to choose carefully in order to avoid setting up structures that have not undergone rigorous production tests, which would then force operators to select alternative pathways and, more importantly, hinder the pre-analytical phase inside the laboratory.

Once consolidation has been achieved, the different platforms can be combined, a process that we call integration. This involves a chain connection between them (the track), a structure that will convey samples around the platforms, substantially improving sample traceability, organizational processes and distribution, as well as supporting workflows and reducing the amount of unproductive tasks. This, in turn, ensures greater resource optimization such as sample centrifugation, transport and preservation if the track includes refrigerators for storage purposes. Moreover, the sample can be retrieved automatically if test confirmation or further testing is required. This simplifies matters considerably and reduces turnaround time (TAT), as well as process-related risks [17].

\section{INTEGRATION IS NOT ONLY A MATTER OF TECHNOLOGY, BUT ALSO A CONCEPTUAL ISSUE}

The fact that some parameters cannot be automated, or integrated into the track for other reasons, does not disrupt the organizational idea at all since integration for the sake of improving production is not only technical but equally a matter of "conception", the notion of significantly improving the lab's organizational structure. At the end of the day, automation generates a "new organizational concept", hence all extra-track technologies that require those parameters will be organized according to the same criteria. Depending on their individual features, tasks are then performed in the processing area; or in the knowledge area if they have a small production volume and require special attention.

Consequently, there are many ways in which CORE-Lab technology supports distribution, aliquotation and conveyance of each sample to its specific processing area. Under this structure, the lab preserves the organizational criteria of production and knowledge areas.

\section{PRODUCTION AND KNOWLEDGE IN THE CORE- LAB: SUPPORT ACTIVITIES}

In the last few paragraphs we have only briefly mentioned support activities when discussing laboratory definition and production area design. However, they are important for the reorganization and reengineering processes that act as bridges between those areas (Fig. 1).

We must keep in mind that, under the organizational structure previously described, knowledge areas significantly reduce their productive activity, as well as their amount of support activities.

For this reason we would like to propose a new notion regarding "support activities". Since they are shared by all laboratory areas, they contribute to avoiding overlaps. Resources are brought together and shared, so that instead of each small area having its own management needs, these activities become much simpler and hence leave more room and time for professionals to set aside unproductive tasks and focus instead on knowledge; which in turn improves their training and their expert contribution to health care [1].

We consider that these support activities act as a "bridge" between both areas, and define some of them as follows:

- Joint management of the Laboratory Area, which successfully unifies and channels work criteria

- $\quad$ Shared non-medical staff - the Core lab processes all samples, whatever their specialty area, and shares technical staff

- The smallest possible number of devices, thus reducing breakdown rates and maintenance costs

- A joint procurement and supply structure 


\section{PRE ANALYTICAL PHASE}

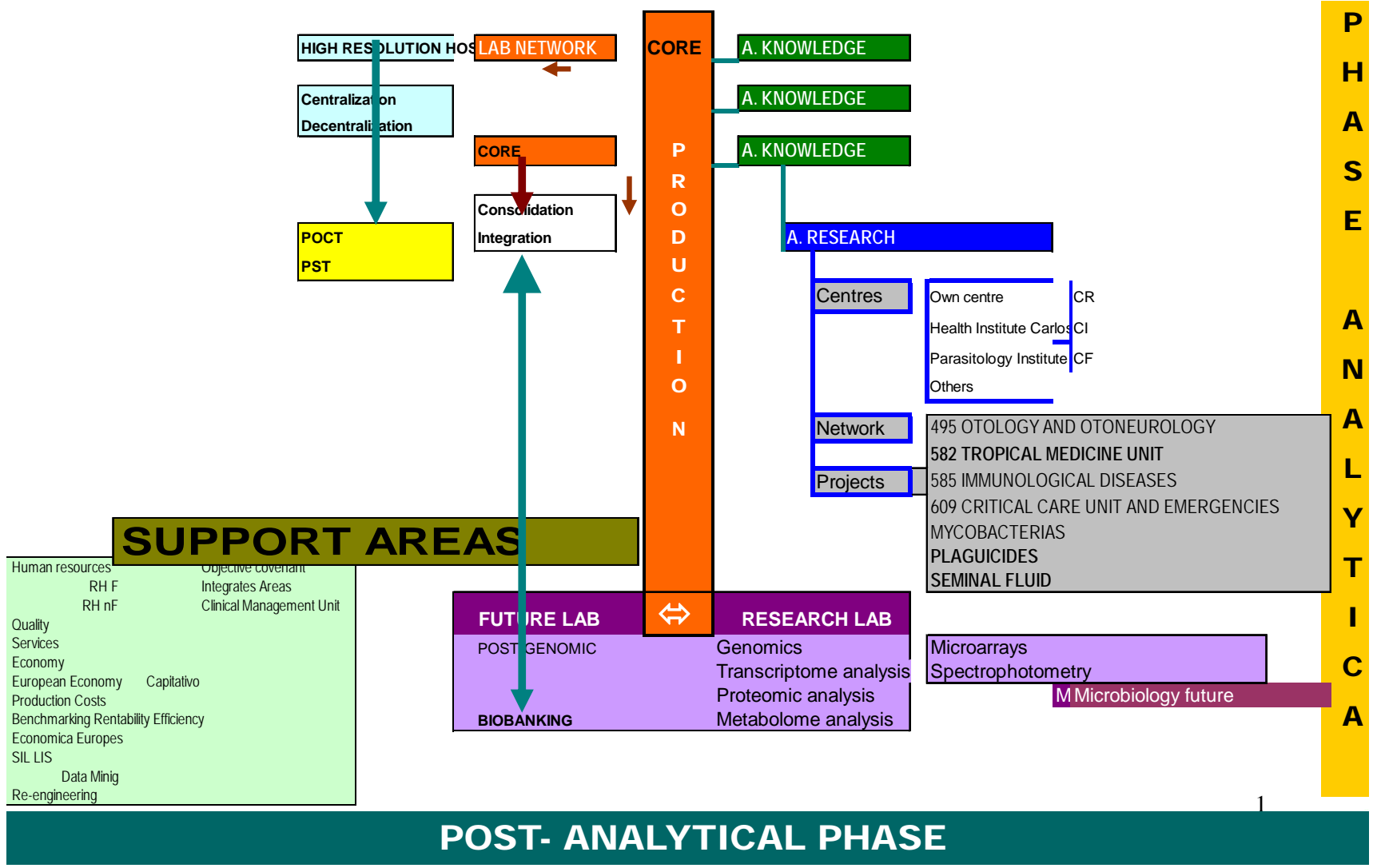

Fig. (1). Schematic representation of the Core Lab.

- Joint quality assurance activities, only one head of quality and control in pre-analytical, analytical and post-analytical phases

- A joint support structure for research and educational activities

- A common laboratory information system (LIS)

- A joint sample-taking and reception structure

- $\quad$ Shared administrative management

- $\quad$ Shared indicator and activity monitoring

Physicians are no longer responsible for these shared tasks, which we consider to be lab support activities, and so they are more available for educational purposes and for the sharing of knowledge.

\section{SEROLOGY AND VIROLOGY IN TODAY'S LABORATORY}

This section summarizes the main purpose of this document, which is to discuss automation processes in virology. I would have found it impossible to approach this without first looking more broadly at automation concepts in existing labs because the organizational developments previously described are relatively recent and have only appeared over the last few decades.

Having said that, from my point of view there is no clear distinction between those labs and the biotechnology area in which I work, and the same holds true for other areas currently under development. We are considering a laboratory that shares resources, and includes a knowledge area and a processing area. Along these lines, automation, virology, and serology as a whole, follow the same criteria as any other methodology. This means that their samples are processed in exactly the same way as any other sample, coming in through the same access point and following the steps included in CORE production. With high prescriptionvolume samples, which adapt to track platforms, they are processed along the track; or in alternative areas when dealing with a lower production volume; as well as in manual or semi-automated systems included in the knowledge area - but always according to the same organizational criteria [10].

Our laboratory has an automated system called "Power Processor", developed by Beckman Coulter and acknowledged as the first organizational project using this system; thanks to which we were awarded a European Reference Laboratory distinction, as is shown in Fig. (2).

In our viral serology system, high-volume processing parameters such as human immunodeficiency virus, hepatitis $\mathrm{C}$ virus, hepatitis $\mathrm{B}$ virus, rubella and toxoplasmosis, amongst others, access the analytical platforms integrated into the track through our global classification system. If they require specific procedures such as confirmation or further more complex testing, they are passed on through the internal automated distribution system to experts in serology, who then decide on which further processing they need. 


\section{AUTOMATION SERUM SAMPLE}

\section{POWER PROCESSOR :Clinical Chemistry \& Immunochemistry}
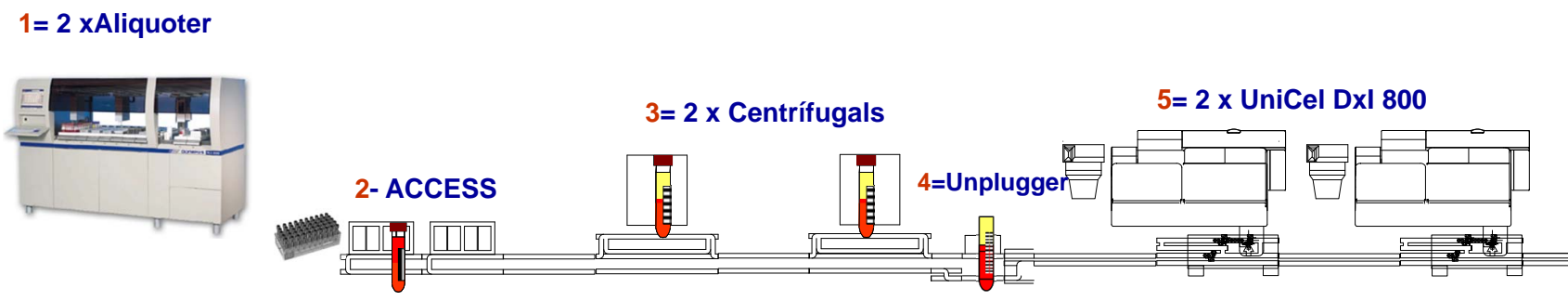

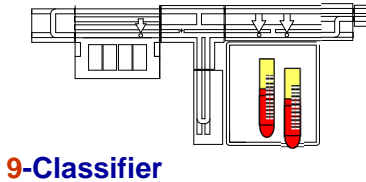

9-Classifier

$8=$ Store

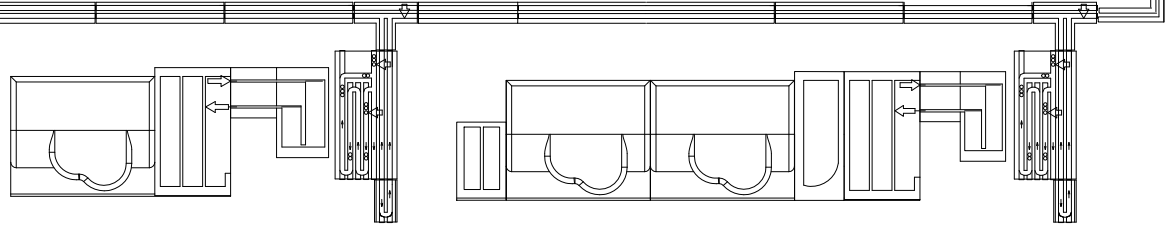

7= Olympus AU 2700

6= Olympus AU 5420

- 1= Two Pre clasifier and alicuoter , 2.000 sample/h

- $\quad$ := Entry track sample , $900 \mathrm{~h}$, and incidents control

- $\quad 3=$ Two Centrifugals , $450 \times 2$ sample /h

- 4= Unplugger $600 \mathrm{sample/h}$
- 5= Immunochemistry auto analyzer ( Serology, tumor markets, hormones.....) 2X400 $=800 \mathrm{Test} / \mathrm{h}$

- 6-7= Two BioChemistry auto analyzer $4400+2100=6.500$ test $/ \mathrm{h}$

- $8=$ Stock area , refrigerated

- $\quad 9=$ Classifier and return sample

Fig. (2). Schematic representation of our laboratory.

The laboratory's IT systems are in charge of granting specialists access to specific parameter validation, always according to their training level and knowledge. For this reason, IT systems must meet the requirements related to each work area and can only grant limited access to a particular user, each of whom needs a specific access code and electronic authorization.

In the past, experts in serology and, more specifically, virology, used to look upon such systems with skepticism, since they were afraid of potential contamination risks when processing serological samples together with other samples, such as hormones or tumor markers, on shared immunochemistry platforms. It has been proven, however, that these types of samples can be processed on the same platform and with the same technology without any problems, which means that they can use shared resources. Furthermore, new technologies have evolved considerably, particularly those based upon immuno-chemiluminiscence.

Thus, a shared immunochemistry platform should not pose any more problems than another devoted exclusively to virology sample processing. If quality control procedures were to become ridiculously sophisticated, individual processing of each serology marker would have to be considered, leading to an impossibly non-operational, inefficient, costly and low-performance situation.

\section{QUALITY ISSUES: THE SIGNIFICANCE OF AUTOMATING CORE-LABS IN THE PRE- ANALYTICAL PHASE}

It is well known and widely reported that pre-analytical errors are a frequent occurrence in the laboratory as a whole. Some authors, such as Plebani, go as far as to say that around $70 \%$ [18-20] of lab errors happen in the pre-analytical phase. According to classical and current criteria, this phase can be divided in two:

- $\quad$ Pre-analytical phase outside of the lab, including all processes and circuits undergone by samples before they reach the laboratory, ranging from prescription to reception, with identification, sample-taking, organization and transport in between.

- $\quad$ Pre-analytical phase in the lab, including everything from reception up to the final placement into the selfanalyzers and the issuance of reports, including all the circuits and pathways followed by samples while they are processed on the different platforms.

There is now well-founded evidence that the organizational structure of both integrated laboratories and 
CORE-Lab areas bring about a clear reduction in preanalytical lab errors thanks to better transport systems. In our laboratory area, these systems are barely visible, but are directly responsible for the improvement in sample locating and traceability.

In this section, when considering sample organization and workflow, we must mention the ever-increasing presence of aliquoter and classification systems, which can be integrated, or not, into the track. In our lab, they are not integrated but play a significant role in sample selection to further convey them to their processing areas. Using unequivocal aliquotation procedures and with no user intervention, these procedures are additionally simplified in order to securely route the sample and to direct an aliquot or a fraction requiring special processing (such as antigen or viral antibody detection), or a sample particularly prone to contamination if passed through the entire platform system; this is directly sent to its specific processing area, significantly reducing the potential for carry-over contamination.

\section{HIERARCHICAL NETWORKS AND POINT OF CARE}

By constantly bearing these organizational criteria in mind, which are aimed at bringing together laboratory areas in order to improve their structural integrity and (very importantly) their economic efficiency - thanks to economies of scale, clinical laboratories must not be isolated from one another, but instead form hierarchical networks so as to make the most of available resources and, above all, of the service portfolio. Accordingly, they should be able to fall back on one another as reference labs. New technologies, transport systems and information and communication technology (ICT) can provide immediate results that are not necessarily generated on site [21, 22]. A very important aspect for the sustainability of these lab networks are the momentous breakthroughs in Point of Care technology [2325]. Thanks to this technology, it is becoming ever easier to take bedside samples. Particularly when it comes to serology tests, mono-test systems allow small laboratories which depend on a central lab, to broaden their service portfolio, and hence to make a much more rational use of their resources, providing the main production is still performed by the central lab.

\section{APPLICATIONS IN LAB MANAGEMENT}

The final and probably most important items in the entire organization and management structure are IT systems - or rather LIS. Without a proper LIS system, it would be utterly impossible to implement the ideal reorganization and reengineering process [26].

IT systems started out by simply generating and filing lab test data. Later, they began communicating with processing systems or auto-analyzers, passing on their data to the LIS and thus dramatically reducing administrative costs. This development had a double impact on result quality, as it required no user intervention, which in turn reduced the number of errors, while, at the same time, it led to improved performance and lower global costs.

Currently, LIS systems are the heart and soul of any laboratory. They include every tool required for lab organization and management, as well as specific modules for each specialty field in the clinical lab. They have no idiosyncratic features, but instead come together as shared systems for all the professionals involved. Our integrated laboratory area now has a single IT system shared by all departments and specialties.

\section{RESULTS AND COST REDUCTION - A SIGNIFICANT ADVANTAGE}

In terms of lab organization and automation, which includes serology and thus virology, final results are simply spectacular, both from an organizational and a financial point of view. However, this has not come at a cost to either care quality or result accuracy. On the contrary, these have also improved dramatically.

At the same time, the points discussed in this paper significantly improve technical and human resource management. Once reorganized, they immediately reduce global lab costs significantly, both directly and indirectly, by increasing processing capabilities yet requiring no additional resources to do so. Economies of scale dramatically reduce lab costs without damaging service quality in the least. In fact, in our case, we are convinced that this process has helped ensure higher quality.

In conclusion, let me highlight once again the importance of Clinical Laboratory Managers, professionals with a profound knowledge of all financial, clinical and organizational issues relevant to a clinical lab, people who are able to implement cost rationalization and reduction measures according to objective criteria in order to achieve real, long-term effects.

\section{CONFLICT OF INTEREST}

The author declares that they have no competing interests.

\section{ACKNOWLEDGEMENTS}

Declared none.

\section{REFERENCES}

[1] Yales I. Strategies for Implementing Successful Laboratory Automation, Agilent Automation Solutions. April 2011. Available from: http://www.chem.agilent.com/Library/posters/Public/Strateg ies_for_Implementing_Successful_Laboratory_Automation.pdf.

[2] Forsman RW. Why is the laboratory an afterthought for managed care organizations? Clin Chem 1996; 42: 813-6.

[3] Wians FH Jr. Clinical Laboratory Tests: Which, Why, and What Do The Results Mean? Lab Med 2009; 40: 105-13.

[4] Hindriks FR, Bosman A, Rademaker PF. The significance of indirect costs-application to clinical laboratory test economics using computer facilities. J Automat Chem 1989; 11: 174-8.

[5] Steiner JW, Murphy KA, Buck EC, Rajkovich DE. How to utilize benchmarking in the clinical laboratory. Clin Leadersh Manag Rev 2006; 20: E4.

[6] Avivar C. Benchmarking Club Hospital Laboratories. Conference in the International University of Andalucía 2012, April 17; Baeza (Jaén), Spain.

[7] Counts JM. Washington Clinical Laboratory Initiative: a vision for collaboration and strategic planning for an integrated laboratory system. Clin Leadersh Manag Rev 2001; 15: 97-100

[8] Caballé I. SEQC meeting. Conference "El Laboratorio del Futuro". 2012, November 18; Granada, Spain.

[9] Catálogo U.C.R. CMS. Center for Medicare \& Medicaid Services. Clinical Laboratory Fee Schedule. Unidad Complejidad Relativas (UCR). Available from: http://www.cms.gov/Medicare/MedicareFee-for-Service-pyment/ClinicalLabFeeSched. 
[10] Galar A, Leiva J, Espinosa M, Guillén-Grima F, Hernáez S, Yuste JR. Clinical and economic evaluation of the impact of rapid microbiological diagnostic testing. J Infect 2012; 65: 302-9.

[11] Avivar C. Memoria Anual: Área Integrada de Biotecnología. Empresa Pública Hospital de Poniente. 2012, April. Available from: http://www.juntadeandalucia.es/ep-hospitalponientealmeriam emorias.php?anyo=2012

[12] Per Capita Total Health \& Clinical Laboratory Expenditure (2008). Health Expenditure Per Capita. Available from: http://www.globalh ealthfacts.org/data/topic/map.aspx?ind=66.

[13] Avivar C. Asociación Española de Biopatología Médica. Conference: Aplicación de los Sistemas Robotizados en el Laboratorio Clínico. Reingeniería de Laboratorio, automatización, Sistemas Robotizados y Petición Electrónica. 2009, October 29; Madrid, Spain.

[14] Friedman BA. The total laboratory solution: a new laboratory Ebusiness model based on a vertical laboratory meta-network. Clin Chem 2001; 47: 1526-35.

[15] Price CP. Evidence-based laboratory medicine: supporting decision-making. Clin Chem 2000; 46: 1041-50.

[16] Bossuyt X, Verweire K, Blanckaert N. Laboratory medicine: challenges and opportunities. Clin Chem 2007; 53: 1730-3.

[17] Kilgore ML, Steindel SJ, Smith JA. Evaluating stat testing options in an academic health center: therapeutic turnaround time and staff satisfaction. Clin Chem 1998; 44: 1597-603.

[18] Plebani M. The detection and prevention of errors in laboratory medicine. Ann Clin Biochem 2010; 47: 101-10
[19] Carraro P, Plebani M. Errors in a stat laboratory: types and frequencies 10 years later. Clin Chem 2007; 53: 1338-42.

[20] Kemp GM, Bird CE, Barth JH. Short-term interventions on wards fail to reduce preanalytical errors: results of two prospective controlled trials. Ann Clin Biochem 2012; 49: 166-9.

[21] Avivar C. Memoria organizativa y Funcional de un Área de Biotecnología de Alta Resolución. Memoria instalación Laboratorio Hospital Alta Resolución del El Toyo, April 2003.

[22] Avivar C. Memoria organizativa y Funcional de un Área de Biotecnología de Alta Resolución. Memoria instalación Laboratorio Hospital Alta Resolución de Loja, April 2010.

[23] Avivar C. XIV Reunión SEDIGLAC. Conference: Implicación del Laboratorio en la Asistencia de Alta Resolución. Centros Alta Resolución: Atención del Laboratorio en las Urgencias y Acto Único. 2010, April 14; Sevilla, Spain.

[24] Information Dynamics 2008. Hospital Decentralized Testing Market Monitor. Available from: http://www.informationdynamics. net/PDF/DTMM2008.pdf

[25] Benayas P, Cabeza MI, Avivar C. Point of Care Testing Glucométros: Programa de Implantación Hospital de PonienteHAR El Toyo-Har Guadix. XX Congreso Latinoamericano de Patología Clínica ALAPAC/ML VII Congreso Nacional de Patología Clínica/ML. X Congreso nacional de Patología/ML. VI Curso Nacional de Citología. 2010, November 17; Quito, Ecuador.

[26] Oller C, Avivar C. I Reunión de Usuarios Openlab. Conference: Modelo de integración de laboratorios del Hospital de Poniente. 2009, March 12; Madrid, Spain.

(c) Cristóbal Avivar; Licensee Bentham Open.

This is an open access article licensed under the terms of the Creative Commons Attribution Non-Commercial License (http: //creativecommons.org/licenses/by$\mathrm{nc} / 3.0 /$ ) which permits unrestricted, non-commercial use, distribution and reproduction in any medium, provided the work is properly cited. 